account of sudden infant death syndrome and non-accidental injury. The remaining 12 chapters are devoted to systematic pathology; only skin and eyes are omitted. The text is uniformly sound and in the case of metabolic diseases and the chapter on muscle and peripheral nerve there is a useful practical section on techniques of investigation. The illustrations are of high quality.

The uneven balance of the content is largely pre-empted by the declared editorial aim that this is not a comprehensive text or reference book. It is intended for pathologists with a special interest in this field rather than a special training. However, some chapters are comprehensive already and I hope that Professor Berry may reconsider the present selective policy for future editions, which should be assured to judge by this volume.

ANGUS GIBSON

\section{Books for patients and parents}

Churchill Livingstone Patient Handbooks No 2: Epilepsy Explained. By M V Laidlaw and $J$ Laidlaw. Pp. 83: $£ 1 \cdot 30$ paperback. No 3: Help for Bed Wetting. By R Meadow. Pp. 43: 95 pence paperback. No 4: Your Child's Development in the First Five Years. By R S Illingworth. Pp. 72: $£ 1 \cdot 20$ paperback. No 5: The Diabetic Child. By J W Farquhar. Pp. 113: $£ 1 \cdot 30$ paperback. No 6: Infections and Immunisation of Your Child. By R S Illingworth. Pp. 73: $£ 1 \cdot 20$ paperback. Edinburgh: Churchill Livingstone, 1982.

I have just been listening to Mozart's A Major piano concerto No 23 (K 488) played by Pollini; the most sublime of composers and one of the greatest of modern pianists; genius interpreted by genius; perfection. In a way, and on an entirely different plane, the writing of books for patients and the parents of patients is similar to a musical performance in so far as for complete success you must have both the corpus of knowledge and experience (the composition) and the ability to interpret it to the readers for whom it is intended (the performance). In another way however the analogy. stands completely inverted because, whereas in music there are few composers and many performers, in the writing of popular books on medical subjects there are many with the qualifications to compose but relatively few with the ability to interpret well. It would be easy to suppose that this kind of writing requires less effort than writing for professional readers but the opposite must be true. I heard it said of the late Ronnie MacKeith that he once interrupted a meeting with 'Yes, but what we ordinary mums want to know is ...?' How many of us really know what we ordinary mums want to know?

So far in this series there are eleven books, six of them (the five I've read and another on Diabetes in your teens) deal with paediatric subjects. They are attractively produced, small books each with a different coloured, bright, glossy, soft cover, measuring $18.5 \times 12.5 \mathrm{~cm}$ and containing between 43 and 115 pages. There are a few simple diagrams and occasional tables and figures, but no photographs. Each of the authors is a nationally or internationally acknowledged authority on his or her subject and has written extensively about it before. As might be expected the factual content of the books is largely impeccablethough the Laidlaws' assertion that $10 \%$ of children with febrile convulsions later develop epilepsy is a gross overestimate.

There are traps which lie in wait for anyone who writes this kind of book and some of the authors have occasionally fallen into them. There is the trap of talking down to people, one facet of which is the use of over-elaborate simile; Professor Farquhar's reference to 'the movie camera at the back of the eye known as the retina' seems to me to come into that category. There is the trap of oversimplification which may confuse rather than illuminate-the Laidlaws' diagrammatic egg-shaped brain divided into exchange brain, computer brain, and primitive brain is an example; I can see no real advantage of an egg-shaped brain over a brain-shaped brain. There is the trap of letting your enthusiasm run away with you. Professor Illingworth can't really expect to get away with 'On no account let your child come in contact with an adult who has, or has had, tuberculosis even though it is said to have "healed" or to be inactive'. The morphological similarity between Koch's bacillus and Hansen's bacillus doesn't justify treating all those who have ever been victims of the former in a way whech used to be reserved for those of the la fier. There is the trap of tautology. Teachers should be grateful for a marvel $\bar{\Phi}$ us example: 'the BS 1619 contains 20 由 in $1 \mathrm{ml}$, but it will only do so when Fou use soluble insulin at a strength of 20 units in one ml'. There is the trap of preaching a sermon rather than gioing professional advice-witness Profesoror Illingworth's exhortation to parents under the heading 'set a good example'. TRere is the trap of being 'groovy' and talking like a Radio 1 disc jockey-'16 uniftuat 80 strength is only 4 on the syringe and 16 units at 40 strength is only 8 onfthe syringe. Got it?' (Lest I be accusedr of favouritism let me say quickly that I examined the short book on enuresistby the senior editor of this journal ifpost carefully for such slip-ups and it galloume considerably to have to admit that I didn't find any). I am also aware that we all fall into such traps from time to time and I claim no immunity, especially pom the trap of enthusiasm.

Who will these books help? Deşite the traps the one about the diabetic s. sild is invaluable as a supplement to direct explanation and discussion with farefnts and all children's departments should have copies to lend. The onecabrout enuresis should also prove help intelligent parents and general practitioners might find it useful to $\overline{\text { fave }}$ several copies for them to lend. I fond the book about epilepsy less readabl@but that may be a personal reaction to the style and many patients or parents night well find it useful, especially in proviging points for further discussion with doctor.

I am not sure how Professor IAfingworth's two books will be used; thereare several longer and much more attractirely presented books which deal with ma of the same subjects. The book abouf infections and immunisations could be useful to parents as a reference book in times of trouble but the absence of an index detracts from its use in that Again, general practitioners wishing: to encourage health education might nconsider both books as an addition t 8 , or a replacement for, Punch and Nothe Illustrated London News in their sufgery waiting rooms.

D $\mathbf{P}$ 